\title{
The High Incidence of Valproate Hepatotoxicity in Infants May Relate to Familial Metabolic Defects
}

\author{
R.E. Appleton, K. Farrell, D.A. Applegarth, J.E. Dimmick, L.T.K. Wong and A.G.F. Davidson
}

\begin{abstract}
The incidence of fatal hepatic failure associated with valproic acid (VPA) therapy is highest in children under the age of three years, particularly in those with developmental delay. The pathogenesis of VPA hepatotoxicity is unclear but may relate to the accumulation of a toxic metabolite of VPA which impairs fatty-acid oxidation. We describe two unrelated infants with developmental delay who developed hepatic failure while receiving VPA. Siblings of both children subsequently developed hepatic steatosis and intractable seizures without being exposed to VPA. This suggests that that the two children who developed liver failure when receiving VPA may have had a familial metabolic disorder. Familial metabolic disorders may account partly for the higher incidence of fatal hepatotoxicity described in infants receiving VPA.
\end{abstract}

\begin{abstract}
RÉSUMÉ: L'incidence élevée d'hépatotoxicité due au valproate chez les nourrissons est peut-être reliée à des anomalies métaboliques familiales L'incidence de l'insuffisance hépatique fatale associée au traitement par l'acide valproïque (AVP) est plus élevée chez les enfants en bas de trois ans, particulièrement chez ceux qui ont un retard de développement. La pathogenèse de l'hépatotoxicité due à l'AVP n'est pas claire, mais elle peut être en relation avec l'accumulation d'un métabolite toxique de l'AVP qui entrave l'oxidation des acides gras. Nous décrivons le cas de deux nourrissons non apparentés ayant un retard de développement, qui ont développé une insuffisance hépatique sous AVP. Des membres de la fratrie des deux enfants ont ultérieurement développé une stéatose hépatique et des convulsions résistantes au traitement sans exposition à l'AVP. Ceci suggère que les deux enfants qui ont développé une insuffisance hépatique sous AVP avaient peut-être une anomalie métabolique familiale. Les anomalies métaboliques familiales peuvent être en partie responsables de l'incidence plus élevée d'hépatotoxicité fatale décrite chez les nourrissons recevant de l'AVP.
\end{abstract}

Can. J. Neurol. Sci. 1990; 17:145-148

Two retrospective studies have described an incidence of fatal liver failure of between one in $500-800$ in children less than three years of age who received valproic acid (VPA) polytherapy. 1,2 The effect of polytherapy on VPA hepatotoxicity may relate to the known induction of cytochrome P-450 mediated metabolism by phenobarbital, phenytoin and carbamazepine. Cytochrome P-450 mediated metabolism is involved in the formation of 4-ene VPA, an unsaturated metabolite which has been implicated in the hepatotoxicity associated with VPA. ${ }^{3}$ The higher incidence of fatal VPA hepatotoxicity in infants and young children has not been explained. The pathogenesis of severe VPA hepatotoxicity is not clear but the microvesicular hepatic steatosis described in these patients is consistent with a disturbance of mitochondrial function and/or fatty-acid metabolism. ${ }^{4}$ We describe two unrelated infants receiving VPA who developed fatal hepatic failure. Both children had siblings who developed hepatic steatosis without being exposed to VPA. This suggests that an inborn error of metabolism may have been present in the two infants who developed hepatic failure when receiving VPA.

\section{Case Reports}

\section{Patient I}

This boy was born to non-consanguineous parents at term following an uneventful pregnancy. The delivery, birth weight and perinatal period were normal. The patient was well until nine months of age when, following a brief febrile illness, he developed acute infantile hemiplegia with hemiconvulsions. Seizure control was achieved with difficulty using phenobarbital, phenytoin, diazepam and paraldehyde. Investigations revealed the following abnormalities: aspartate aminotransferase (AST) $199 \mathrm{U} / \mathrm{L}$, alanine aminotransferase (ALT) $60 \mathrm{U} / \mathrm{L}$, fibrinogen $67 \mathrm{mg} / \mathrm{dl}(0.67 \mathrm{~g} / \mathrm{L})$, glucose $120 \mathrm{mg} / \mathrm{dl}(6.6 \mathrm{mmol} / \mathrm{L})$ and

From the Department of Pediatrics (R.E.A., K.F., D.A.A., L.T.K.W., A.G.F.D.) and Pathology (D.A.A., J.E.D.), British Columbia's Children's Hospital, University of British Columbia, Vancouver

Presented at the XXIIIrd Canadian Congress of Neurological Sciences, Quebec City, June 1988

Received September 11, 1989. Accepted in final form December 11, 1989

Reprint requests to: Dr. Kevin Farrell, British Columbia's Children's Hospital, 4480 Oak Street, Vancouver, British Columbia, Canada V6H 3V4 
prothrombin time 11.8 seconds. The serum ammonia, lactate, electrolytes, protein, glucose and cell count in the cerebrospinal fluid, urinary VMA studies and computed tomography (CT) of the head were normal.

Myoclonic seizures were observed after three weeks and the child received VPA ( $35 \mathrm{mg} / \mathrm{kg} /$ day) for three days. The serum AST activity was $91 \mathrm{U} / \mathrm{L}$ when measured on the day after starting VPA. Myoclonus persisted and VPA was discontinued. One week after discontinuing VPA, investigations revealed the following: AST $320 \mathrm{U} / \mathrm{L}$, total bilirubin $8.5 \mathrm{mg} / \mathrm{dl}(144.5 \mathrm{umol} / \mathrm{L})$ and prothrombin time 15.7 seconds. The liver failure worsened and he died three months after the onset of the seizures. Autopsy revealed diffuse necrosis, steatosis and fibrosis of the liver and an acute duodenal ulcer.

An older sister of Patient 1 had been born at term following a normal pregnancy. The birth weight and perinatal period were normal. This child was well until four months of age, when she failed to thrive following the introduction of cereals. No investigations were performed. At nine months of age the child developed an illness characterized by vomiting and lethargy. Ten hours after the onset of vomiting she was found dead in her crib. Autopsy revealed diffuse steatosis of the liver and a small, perforated duodenal ulcer.

A younger sister of Patient 1 was born following a normal pregnancy; the delivery, birth weight and perinatal period were normal. This child was well until three months of age, when she presented with feeding difficulties and failure to thrive. She was initially breast fed but feeding continued to be poor on changing to Prosobee together with an addition of cereals and Caloreen. At six months of age hepatomegaly was observed. The serum AST and ALT activities were elevated at $113 \mathrm{U} / \mathrm{L}$ and $126 \mathrm{U} / \mathrm{L}$ respectively. A needle biopsy of the liver revealed steatosis, minimal necrosis, no evidence of abnormal glycogen storage, no organelle pathology by electron microscopy. Electron microscopy was normal. Recurrent fasting hypoglycemia associated with dicarboxylic acid uria was noted but, despite intensive investigation (see below), an underlying cause was not demonstrated.

She was fed by nasogastric tube, gained $2.6 \mathrm{~kg}$ in weight and was discharged home at eight months of age. At nine months of age she developed focal motor and generalized seizures. The liver was enlarged and the serum AST and ALT activities were elevated at $333 \mathrm{U} / \mathrm{L}$ and $230 \mathrm{U} / \mathrm{L}$ respectively. The blood glucose, serum ammonia and head CT were normal. The seizures were controlled temporarily using phenobarbitone, phenytoin and lignocaine. She received also oral carnitine ( $2 \mathrm{gm} / \mathrm{day})$ and oral pyridoxine ( $400 \mathrm{mg} / \mathrm{day})$. Over the next 36 hours the patient developed hepatic failure and she died one week after the onset of the seizures. Findings of a metabolic autopsy, performed within an hour of death, again revealed only marked steatosis and necrosis of the liver.

Investigations in this child demonstrated recurrent, fasting hypoglycemia but failed to demonstrate the underlying mechanism. A 4 hour fasting glucose was $36 \mathrm{mg} / \mathrm{dl}(2.9 \mathrm{mmol} / \mathrm{L})$ with normal insulin levels. Increased levels of urinary dicarboxylic acids, plasma free fatty acids and beta-hydroxybutyric acid were demonstrated following a fast but urinary organic acids were normal on two other occasions. Serum free and total carnitine concentrations were normal as was the ratio of esterfied to free carnitine. Oral fructose $(1 \mathrm{G} / \mathrm{kg}$ ) tolerance and oral glycerol $(1 \mathrm{G} / \mathrm{kg}$ ) loading tests gave normal glycemic responses. Intravenous glucagon $(0-25 \mathrm{mg})$ only produced an increase in blood glucose after a two hour fast but no response on more prolonged fasting of over 6 hours. An oral alanine load $(0.5 \mathrm{~g} / \mathrm{kg})$ resulted in a progressive fall in the level of blood glucose, from $81 \mathrm{mg} / \mathrm{dl}(4.1 \mathrm{mmol} / \mathrm{L})$ to $56 \mathrm{mg} / \mathrm{dl}$ $(3.1 \mathrm{mmol} / \mathrm{L})$, over a two hour period and was associated with a rise of blood lactate (Table 1). Phosphoenolpyruvuate carboxykinase activity in skin fibroblasts and liver (cytosol and mitochrondrial fractions) was within the normal range. Short chain, medium chain and long chain acyl CoA dehydrogenase activities in fibroblasts were normal. In addition, plasma octanoic acid and urinary octanoyl carnitine concentrations were normal. The following investigations were normal or negative: $\mathrm{CBC}$ and blood film, coagulation studies, serum fibrinogen, bilirubin, albumin, BUN, creatinine, electrolytes, ammonia, fasting lactate, cholesterol and triglycerides, plasma amino acids, copper, ceruloplasmin, thyroid function studies, immunoglobulin electrophoresis, sweat test $\left(\mathrm{x}_{2}\right)$, alpha- 1 antitrypsin, hepatitis $B$ surface antigen and viral antibody studies (for hepatitis A, cytomegalovirus, Ebstein-Barr, herpes simplex, rubella and measles).

\begin{tabular}{lrrrrr}
\hline \multicolumn{1}{l}{ Table 1: Alanine Tolerance Test } & & & & & \\
\hline \hline TIME (min) & $\mathbf{0}$ & $\mathbf{3 0}$ & $\mathbf{6 0}$ & $\mathbf{9 0}$ & $\mathbf{1 2 0}$ \\
\hline Glucose (mg/dl) & 81 & 81 & 67 & 63 & 56 \\
Alanine (micromol.) & 262 & 3266 & 3449 & - & 3603 \\
Lactate (mmol.) & 1.1 & - & 1.8 & 2.5 & 2.8 \\
\hline
\end{tabular}

Alanine $(2.6 \mathrm{gm})$ was given at Time 0 .

\section{Patient 2}

This boy, the first child of non-consanguineous parents, was born following a normal pregnancy and delivery. The birth weight and perinatal period were normal. At three months of age brief episodes of head shaking and arm stiffening were observed, which were not investigated and which resolved spontaneously by five months. The child's gross motor development was slow and he could not sit without support at nine months of age. At ten months of age the child presented in status epilepticus following a mild respiratory illness. He was treated with phenobarbitone, phenytoin, diazepam, thiopentone and lignocaine. The serum activities of AST and ALT were elevated at $72 \mathrm{U} / \mathrm{L}$ and $55 \mathrm{U} / \mathrm{L}$ respectively. Computed tomography of the head was normal. Electroencephalography (EEG) showed severe generalized dysfunction with periodic lateralizing epileptiform discharges (PLEDS). Myoclonic seizures developed which were refractory to nitrazepam. Forty-eight hours after receiving VPA the patient was noted to be jaundiced and drowsy. All the anti-epileptic drugs, valproic acid, phenytoin, phenobarbitone and nitrazepam, were discontinued. The patient developed rapidly progressive liver failure and died two months later. Findings at autopsy were atrophy of the cerebral cortex and hepatic steatosis with minimal fibrosis, consistent with a diagnosis of progressive neuronal degeneration of childhood with liver disease.

Investigations in this patient revealed the following abnormal results: AST $233 \mathrm{U} / \mathrm{L}$, ALT $11 \mathrm{U} / \mathrm{L}$, total bilirubin $8.7 \mathrm{mg} / \mathrm{dl}(147.9 \mathrm{umol} / \mathrm{L})$, conjugated bilirubin $6.5 \mathrm{mg} / \mathrm{dl}(110.5 \mathrm{umol} / \mathrm{L})$, serum ammonia $90 \mathrm{microgm} / \mathrm{dl}(53.1 \mathrm{umol} / \mathrm{L})$, total protein $4.1 \mathrm{~g} / \mathrm{dl}(41 \mathrm{~g} / \mathrm{L})$, albumin $2.0 \mathrm{~g} / \mathrm{dl}(20 \mathrm{~g} / \mathrm{L})$, fibrinogen $66 \mathrm{mg} / \mathrm{dl}(0.66 \mathrm{~g} / \mathrm{L})$, prothrombin time 25.8 seconds and serum sodium $129 \mathrm{mEq} / \mathrm{L}(129 \mathrm{mmol} / \mathrm{L})$. CT of the head, (performed one month after the initial CT scan) demonstrated prominent subarachnoid spaces and mild dilatation of the lateral ventricles. The following investigations gave normal or negative results: CBC, BUN, creatinine, serum potassium, plasma amino acids, alpha-1 antitrypsin, immunoglobulin electrophoresis, ceruloplasmin, urinary organic acids, hepatitis B surface antigen and viral studies (for hepatitis A, herpes simplex and zoster, cytomegalovirus, rubella, Ebstein-Barr and measles).

A younger sister of Patient 2 presented at six months of age with developmental delay and raised serum liver transaminase activity. A liver biopsy demonstrated no pathology. At nine months of age, she developed a brief illness characterized by vomiting and lethargy. Twenty-four hours after the onset of vomiting she presented in status epilepticus which was controlled eventually with thiopentone. Electroencephalography demonstrated PLEDS and CT of the head was normal. A repeat liver biopsy revealed microvesicular steatosis and mild, non-specific abnormalities of mitochondrial structure. She was treated with clonazepam, thiamine, vitamin $\mathrm{K} 3$, vitamin $\mathrm{C}$, ribroflabin and carnitine. She did not receive VPA. She developed rapidly progressive liver failure, epilepsia partialis continua and died at 14 months of age. Autopsy demonstrated microvesicular hepatatic steatosis and necrosis together with cerebral cortical atrophy.

\section{Discussion}

The incidence of fatal VPA hepatotoxicity in children under the age of three years on multiple antiepileptic drugs was one in 500 and one in 800 in two retrospective studies.1.2 Many of these children had unexplained severe neurological abnormalities prior to receiving VPA. Fourteen of the 16 children under three years of age had experienced a recent episode of status epilepticus. ${ }^{1}$ Hepatic failure usually occurred within six months 
of the start of VPA therapy, was not related to dose or serum VPA concentration and progressed despite drug withdrawal. Histological findings in most patients revealed microvesicular hepatic steatosis usually accompanied by necrosis. 1.5

Both of our patients had many of the characteristic features described in young children developing progressive liver failure after being exposed to VPA. Both were under the age of three years, had developmental delay, had recently been in status epilepticus and were receiving other antiepileptic drugs at the onset of the liver failure. In addition, autopsies in both demonstrated hepatic steatosis and necrosis. In view of the clinical course and autopsy findings, the cause of death in each patient was attributed initially to VPA induced hepatic failure. Although increased serum hepatic enzyme activity was observed in both patients prior to receiving VPA, this increase was mild and was attributed to the effects of status epilepticus ${ }^{6}$ or other antiepileptic drugs. 7.8

Autopsies on the two siblings of patient 1 demonstrated hepatic steatosis. The older sibling was found dead in bed following a brief illness characterized by vomiting and lethargy. Patients with inherited disorders of fatty acid oxidation, including medium chain fatty acid acyl coenzyme A deficiency, may present as sudden infant death, ${ }^{9-13}$ or with an illness resembling Reye syndrome. 11,14,15 Extensive investigations including a metabolic autopsy demonstrated no underlying metabolic disease in the younger sibling. The dicarboxylic aciduria suggested the possibility of a defect in fatty acid beta-oxidation. This was also suggested by the presence of microvesicular hepatic steatosis in both older siblings. However, the measurement of long, medium and short chain acyl CoA dehydrogenases in cultured fibroblasts demonstrated activities within the normal range. A defect of gluconeogenesis was also considered in view of the fasting hypoglycemia and inability to convert alanine into glucose. The major demonstrable metabolic abnormality in this patient was an inability to sustain normal blood glucose levels for longer than approximately 4 hours. Infusion of fructose and glycerol both produced a sustained rise in blood glucose whereas infusion of alanine did not. We measured PEP carboxykinase (both cytosolic and mitochondrial) in fibroblasts from this child and obtained activities within the range found for controls. We were therefore unable to demonstrate a defect in gluconeogenic enzymes. Although we have not been able so far to demonstrate a specific enzyme deficiency in this sibling, an inborn error of metabolism was suggested by the hepatic findings and family history.

The autopsy findings of hepatic steatosis with fibrosis and diffuse atrophy of the cerebral cortex in patient 2, together with the history of developmental delay, sudden onset of intractable seizures with subsequent encephalopathy and rapidly progressive liver failure terminating in cirrhosis, suggested a diagnosis of progressive neuronal degeneration of childhood (PNDC) with liver disease. ${ }^{16-19}$ The clinical and neuropathological findings of PNDC are similar to those that were first identified by Alpers in 1931.20 Although liver disease was not described in the children reported by Alpers, subsequent authors have emphasized the association of PNDC with liver disease. 16,18,19

Seven of $10^{18}$ and two of $13^{19}$ children described previously with PNDC had received VPA prior to death. There are similarities in the clinical presentation and liver pathology of both PNDC and VPA-induced hepatotoxicity. Patients with PNDC present usually between one and three years of age with developmental delay and intractable seizures, often beginning as status epilepticus. $16,18,19$ Similarly, fourteen of the sixteen patients under three years of age who developed VPA hepatic failure had experienced a recent episode of status epilepticus.' Refractory myoclonic epilepsy is the seizure type most commonly described in both PNDC 16 and in those children dying from VPA associated liver failure. 1,21 The hepatic pathology in both VPA-associated hepatic failure and PNDC includes microvesicular steatosis and necrosis with or without cirrhosis.5.18 Finally, abnormalities in the structure and function of hepatic mitochondria have been observed both in VPA induced hepatotoxicity 22 and PNDC. ${ }^{23}$ Thus, a reduced mitochondrial content of cytochrome aa3, an enzyme system involved in the function of the respiratory chain of mitochondria, has been described in both rats treated with VPA 22 and in two siblings with PNDC. ${ }^{23}$ PNDC has also been described in patients with pyruvate dehydrogenese complex deficiency in brain, ${ }^{24}$ decreased pyruvate carboxylase activity in liver, ${ }^{25}$ disturbed pyruvate oxidation in liver and muscle, ${ }^{26}$ and a defect in citric acid cycle activity in liver and fibroblasts. 27 Thus, patients with PNDC have inborn errors of metabolism which may be exacerbated by treatment with VPA.

Hepatic steatosis was observed in two siblings of patient 1 and also in the sibling of patient 2 although they had not been exposed to VPA. In addition, the clinical presentations in the younger sibling of patient 1 and the sibling of patient 2 were similar to those of patients 1 and 2. This suggests that both of our patients may have had an underlying metabolic disorder. Inborn errors of metabolism present usually during the neonatal period or infancy. Thus, it is possible that the increased incidence of fatal VPA hepatotoxicity in children under three years of age may relate, at least in part, to the manifestation of familial metabolic defects in this age group. This is supported by the most recent review of valproic acid hepatic fatalities in the United States. ${ }^{2}$ Thus, siblings of three previously reported cases of fatal hepatotoxicity ${ }^{1}$ developed hepatic failure without ever being exposed to VPA. ${ }^{2}$ Similarly, although VPA was associated with fatal hepatotoxicity in siblings in two unrelated families, autopsy findings in these children were consistent with PNDC. 5

The development of hepatic failure in some children with inborn errors of metabolism who were also receiving VPA may be more than coincidental. Glutathione peroxidase deficiency has been described in a child with PNDC. 28 Glutathione has a major role in preventing toxic liver injury both by inhibiting covalent binding of macromolecules and also by protecting against oxidative stress. ${ }^{29}$ Thus, conditions associated with depletion of glutathione may predispose patients to VPA hepatotoxicity. Children with urea cycle disorders may also be predisposed to VPA toxicity. Fatal hepatotoxicity was associated with VPA therapy in a 3 year old girl whose two siblings had also died in early childhood. ${ }^{30}$ All three children had persistent vomiting and convulsions and alanine loading tests in the surviving family members suggested that the children probably had ornithine carbamyl transferase (OCT) deficiency. ${ }^{30}$ Markedly decreased OCT activity has also been demonstrated in a child of 3 years who died of liver failure after receiving VPA.31 Similarly, hyperammonemia was precipitated by VPA therapy in a patient with arginosuccinic aciduria. ${ }^{32}$ The toxic effect of VPA in children with urea cycle disorders may relate to inhibition of 
carbamyl phosphate synthesis by VPA, possibly due to the formation of CoA esters of VPA resulting in a decrease of available free CoA. 33,34

This report describes two unrelated families with probable inborn errors of metabolism where a child died of liver failure following the use of VPA. Inborn errors of metabolism probably contribute to the particularly high incidence of liver failure described in infants and young children receiving VPA polytherapy. Certain metabolic disorders may be exacerbated by VPA. We suggest that infants at high risk should be screened carefully for familial hepatic disease prior to treatment with VPA.

\section{ACKNOWLEDGEMENTS}

The authors gratefully acknowledge the assistance of Dr. S.I. Goodman (Denver, Colorado) for measurement of the long, medium and short chain acyl CoA dehydrogenases and Ms. Jenny Toone for measurement of PEP carboxykinase.

\section{REFERENCES}

1. Dreifuss FE, Santili N, Langer DH, et al. Valproic acid hepatic fatalities. Neurology 1987; 37: 379-385.

2. Dreifuss FE, Langer DH, Moline KA, et al. Valproic acid hepatic fatalities. II. US experience since 1984. Neurology 1989;39: 201-207.

3. Rettie AE, Rettenmeier AW, Howald WN, et al. Cytochrome P450catalyzed formation of 4-ene VPA, a toxic metabolite of valproic acid. Science 1987; 235: 890-893.

4. Powell-Jackson PR, Tredger JM, Williams R. Hepatotoxicity to sodium valproate: a review. Gut 1984; 25: 673-681.

5. Zimmerman HJ, Ishak KG. Valproate-induced hepatic injury: analysis of 23 fatal cases. Hepatology 1982; 2: 591-597.

6. Glaser GH. Medical complications of status epilepticus. In: Delgado-Escueta AN, Wasterlain CG, Treiman DM, Porter EJ, eds. Status Epilepticus, Mechanism of Brain Damage and Treatment. Advances in Neurology (Volume 34). New York: Raven Press 1983: 396-398.

7. Camfield C, Camfield P, Smith E, et al. Asymptomatic children with epilepsy: little benefit from screening for anti-convulsant induced liver, blood or renal damage. Neurology 1986; 36: 838841.

8. Abu-Arafeh IA, Wallace SJ. Unwanted effects of epileptic drugs. Dev Med Child Neurol 1988; 30: 115-121.

9. Howat AJ, Bennett MJ, Variend S, et al. Defects of metabolism of fatty acids in the sudden infant death syndrome. Br Med J 1985; 290: $1771-1773$.

10. Leading article. Sudden infant death and inherited disorders of fat oxidation. Lancet 1986; ii: 1073-1075.

11. Roe CR, Millington DS, Maltby DA, et al. Recognition of mediumchain acyl CoA dehydrogenase deficiency in asymptomatic siblings of children dying of sudden infant death or Reye-like syndromes. J Pediatr 1986; 108: 13-18.

12. Roe CR, Millington DS, Maltby DA, et al. Post-mortem recognition of inherited metabolic disorders from specific acylcarnitines in tissue in cases of sudden infant death. Lancet 1987; i: 512.

13. Harpey JP, Charpentier C, Coude M, et al. Sudden infant death syndrome and multiple acyl-coenzyme A dehydrogenase deficiency, ethylmalomic-adipicaciduria or systemic carnitine deficiency. J Pediatr 1987; 110:881-883.
14. Bougneres PI, Rocchiccioli F, Kolvraa S, et al. Medium-chain acyl CoA dehydrogenase deficiency in two siblings with a Reye-like syndrome. J Pediatr 1985; 106: 918-921.

15. Taubman B, Hale DE, Kelley RI. Familial Reye-like syndrome: a presentation of medium chain acyl-coenzyme $A$ dehydrogenase deficiency. Paediatrics 1987; 79: 382-385.

16. Huttenlocher PR, Solitaire GB, Adams G. Infantile diffuse cerebral degeneration with hepatic cirrhosis. Arch Neurol 1976; 33: 186192.

17. Boyd SG, Harden A, Egger J, et al. Progressive neuronal degeneration of childhood with liver disease ("Alpers' Disease"): characteristic neurophysiological features. Neuropaediatrics 1986; 17 : 75-80.

18. Harding BN, Egger J, Portmann B, et al. Progressive neuronal degeneration of childhood with liver disease. Brain 1986; 109: $181-206$

19. Egger J, Harding BN, Boyd SG, et al. Progressive neuronal degeneration of childhood (PNDC) with liver disease. Clinical Pediatrics $1987 ; 26: 167-173$.

20. Alpers BJ. Diffuse progressive degeneration of the grey matter of the cerebrum. Arch Neurol Psychiatry 1931; 25: 469-505.

21. Green SH. Sodium valproate and routine liver function tests. Arch Dis Child 1984; 59: 813-814.

22. Hayasaka K, Takahashi I, Kobayashi Y, et al. Effects of valproate on biogenesis and function of liver mitochondria. Neurology 1986; 36: 351-356

23. Prick MJJ, Gabreels FJM, Trijbels JMF, et al. Progressive poliodystrophy (Alpers' Disease) with a defect in cytochrome aa3 in muscle: a report of two unrelated patients. Clin Neurol Neurosurg 1983; 85: 57-69.

24. Prick M, Gabreels F, Renier W, et al. Pyruvate dehydrogenase deficiency restricted to brain. Neurology 1981, 85: (NY) 31: 398404.

25. Tommasi $M$, Jouvet-Telinge A, Kopp N, et al. Poliodystrophie cérébrale infantile d'Alpers. Un cas avec anomalie de la pyruvatecarboxylase hépatique. Ann Anat Pathol 1977; 22: 337-342.

26. Prick MJJ, Gabreels JM, Renier WO, et al. Progressive infantile poliodystrophy. Association with disturbed pyruvate oxidation in muscle and liver. Arch Neurol 1981; 38: 767-772.

27. Prick, MJJ, Gabreels FJM, Renier WO, et al. Progressive infantile poliodystrophy (Alpers' Disease) with a defect in citric acid cycle activity in liver and fibroblasts. Neuropediatrics 1982; 13: 108-111.

28. Maertens $P$, Weisman E, Pippenger CE. Free radical scavenging enzyme activities in Alpers disease. Ann Neurology. 1989; 26: 437.

29. Farber JL. Xenobiotics, drug metabolism, and liver injury. Monographs in pathology 1987; 28: 43-53.

30. Hjelm M, de Silva LVK, Seakins JWT, et al. Evidence of inherited urea cycle defect in a case of fatal valproate toxicity. $\mathrm{Br}$ Med J 1986; 292: 23-24

31. Ware S, Millward-Sedler GH. Sodium valproate and omithine carbamyl transferase deficiency. Lancet 1981; ii: 1165-1166.

32. Morgan HB, Swaiman KF, Johnson BD. Diagnosis of argininosuccinic aciduria after valproic acid-induced hyperammonemia. Neurology 1987; 37: 886-887.

33. Marini AM, Zaret BS, Beckner RR. Hepatic and renal contributions to valproic acid-induced hyperammonemia. Neurology 1988; 38: 365-371.

34. Hjelm M, Oberholzer V, Seakins J, et al. Valproate-induced inhibition of urea synthesis and hyperammonemia in healthy subjects. Lancet 1986; ii: 859. 